\title{
Late infra-renal aortic graft infection: a fearsome complication
}

Fernando Peixoto Ferraz de Campos $^{a}$, Erasmo Simão Silva ${ }^{b}$, Nelson De Luccia ${ }^{b}$, Vivian Helena Ribeiro ${ }^{b}$, Brenda Margatho Ramos Martines ${ }^{c}$, João Augusto dos Santos Martines ${ }^{c}$

Campos FPF, Silva ES, De Luccia N, Ribeiro VH, Martines BMR, Martines JAS. Late infra-renal aortic graft infection: a fearsome complication. Autopsy Case Rep [Internet]. 2013;3(1): 45-51. http://dx.doi.org/10.4322/acr.2013.007

\section{ABSTRACT}

\begin{abstract}
Since the 1950s, aortic graft infections (AGIs) constitute one of the most feared complications after reconstructive vascular surgery. This complication is not frequent, ranging from $1 \%$ to $2 \%$ in the recently reported series; however, the high rate of death and morbidity after therapeutic attempts justifies its dreadful fame. The majority of cases occur during the first month after surgery. Staphylococcus aureus is the cause of $70 \%$ of the early infection cases. Late infections, on the other hand, are even rarer, showing a strong relationship with low virulence microorganisms, where Staphylococcus epidermidis is the main cause. Gram-negative bacteria are also observed in late infections, mainly when an aortic or graft enteric fistula is present. Treatment modalities are plenty, but still debatable. The authors report a case of a woman who was operated on 6 years ago for a reconstructive aortic aneurysm with the implantation of an infrarenal Dacron graft in the aorto bifemoral position. She looked for medical assistance with a 2-month history of weight loss, abdominal/ back pain, and fever. Her clinical status rapidly deteriorated. A computed tomography of the abdomen disclosed the diagnosis of an AGI. The patient was promptly treated with antibiotics. Surgery was undertaken to explant the infected graft and another graft was placed into the axillobifemoral position. Culture from the infections site was negative. After surgery the patient quickly developed refractory septic shock and died immediately post-operatively
\end{abstract}

Keywords: Aortic Aneurysm; Vascular Grafting; Infection; Diagnosis.

\section{CASE REPORT}

A 73-year-old female patient, previously diagnosed with hypertension, dyslipidemia, and pulmonary emphysema, sought medical assistance complaining of weight loss of $5 \mathrm{~kg}$ during the last 2 months. She referred back and abdominal pain, mainly in the hypogastrium and left iliac fossa, which worsened until the day of hospital arrival. She referred episodes of melena during the last 2 weeks and one episode of enterorrhagia. More recently, she noted chills and fever of $38{ }^{\circ} \mathrm{C}$. Nausea, vomiting, and loss of appetite were added to this clinical picture. She was taking regularly enalapril, hydrochlorothiazide, and simvastatin. She was a heavy smoker. She underwent a gastrectomy with

\footnotetext{
a Department of Internal Medicine - Hospital Universitário - Universidade de São Paulo, São Paulo/SP - Brazil.

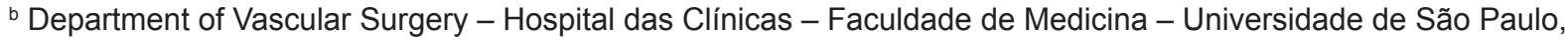

c Diagnostic Imaging Service - Hospital Universitário - Universidade de São Paulo, São Paulo/SP - Brazil.
}

Copyright $\odot 2013$ Autopsy and Case Reports - This is an Open Access article distributed of terms of the Creative Commons Attribution NonCommercial License (http://creativecommons.org/licenses/by/3.0/) which permits unrestricted non-commercial use, distribution, and reproduction in any médium provided article is properly cited. 
Bilroth II reconstruction 10 years ago as she had been diagnosed with a peptic ulcer. Six years ago she was submitted to an infra renal aortic aneurysm angioplasty with a Dacron aorto bifemoral graft for correction of an abdominal aortic aneurysm.

Physical examination showed an illlooking patient, pale, and emaciated. Her blood pressure was 110/70 $\mathrm{mmHg}$; pulse rate was irregular $=90$ beats per minute; respiratory rate $=20$ respiratory movements per minute; and she was afebrile. The heart examination showed arrhythmic cardiac sounds with a systolic murmur; the abdomen was flat, flaccid, but painful on hypogastrium and left iliac fossa palpation. Tenderness was evident on percussion of the left dorsal region. Abdominal sounds were normal, and no signs of peritonitis were detected. Digital rectal examination and anuscopy were normal, and upper gastrointestinal endoscopy ruled out any source of bleeding until the second duodenal portion. The initial laboratory workup is shown in Table 1.

The abdominal ultrasound revealed the presence of patent aortoiliac bifemoral prosthesis, but no abnormalities were detected on the remaining accessible regions. The computed tomography scan of the abdomen revealed a tortuous and atheromatous aorta, slightly dilated in the thoracoabdominal transition.

An infrarenal endoprosthesis in aortobifemoral position was patent, without evidence of contrast leakage, but some tiny images associated with gas and enhancement of surround soft tissue and diffuse blurring of adipose plans around the infrarenal aortic portion were observed, suggesting graft infection (Figures 1 and 2).

Splanchnic arteries were patent and the inferior vena cava showed normal caliber and contours. Lymphadenomegaly was evident in the great vessels chain (Figure 3 ).

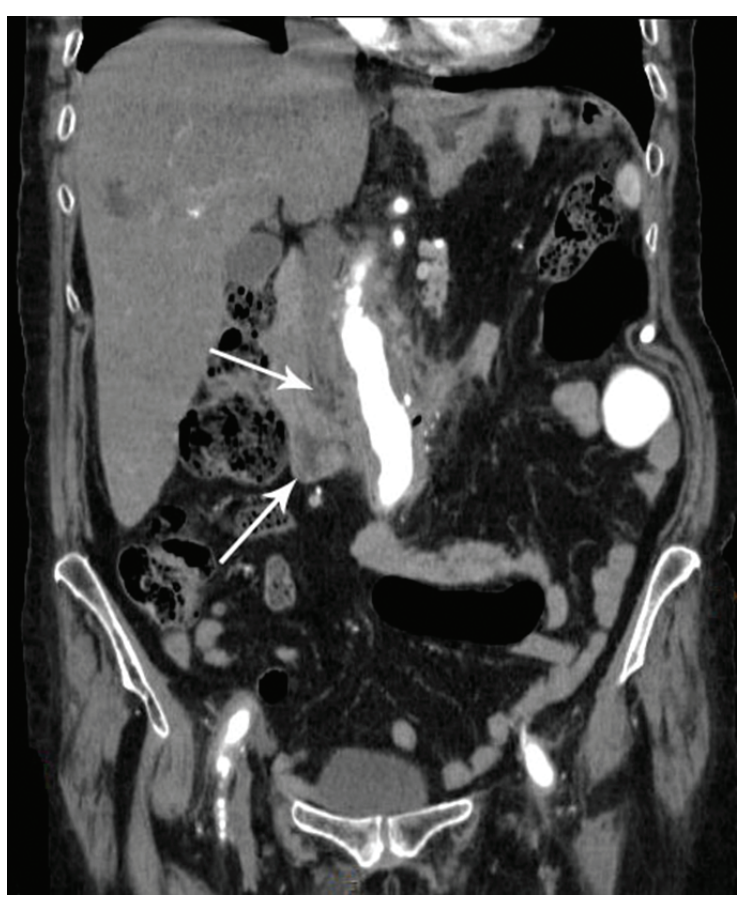

Figure 1 - Computed tomography of the abdomen, arterial phase, and coronal reconstruction. The arrows point to a densification of soft tissue around the aortic prosthesis, with gaseous images in between.

Table 1 - Initial laboratory work up

\begin{tabular}{|c|c|c|c|c|c|}
\hline Exam & Result & RV & Exam & Result & RV \\
\hline Hemoglobin & 9.6 & $12.3-15.3 \mathrm{~g} \%$ & Creatinine & 1.5 & $0.4-1.3 \mathrm{mg} / \mathrm{dL}$ \\
\hline Hematocrit & 28.9 & $36-45 \%$ & Urea & 86 & $10-50 \mathrm{mg} / \mathrm{dL}$ \\
\hline Leukocytes & 18.9 & $4.4-11.3 \times 10^{3} / \mathrm{mm}^{3} 103.10^{3} / \mathrm{mm}^{3}$ & $\mathrm{Na}+$ & 132 & $135-145 \mathrm{mEq} / \mathrm{L}$ \\
\hline Myelocytes & 0 & $0 \%$ & $\mathrm{~K}+$ & 4 & 3.5-5.0 mEq/L \\
\hline Metamyelocytes & 0 & $0 \%$ & & & \\
\hline Bands & 8 & $1-5 \%$ & & & \\
\hline Segmented & 70 & $45-70 \%$ & AST & 13 & $10-35 \mathrm{U} / \mathrm{L}$ \\
\hline Eosinophils & 0 & $1-4 \%$ & ALT & 27 & $9-43 \mathrm{U} / \mathrm{L}$ \\
\hline Basophils & 0 & $0-2.5 \%$ & T Bil & 0.7 & $3-5 \mathrm{~g} / \mathrm{dL}$ \\
\hline Lymphocytes & 13 & $18-40 \%$ & Amylase & 96 & $20-104 \mathrm{U} / \mathrm{L}$ \\
\hline Monocytes & 8 & $2-9 \%$ & & & \\
\hline Platelets & 427 & $150-450 \times 10^{3} / \mathrm{mm}^{3} 10^{3} / \mathrm{mm}^{3}$ & INR & 1.21 & \\
\hline
\end{tabular}

$\mathrm{ALT}=$ alanine aminotransferase; $\mathrm{AST}=$ aspartate aminotransferase; BUN = blood urea nitrogen; INR = international normalized ratio; $\mathrm{K}+=$ potassium; $\mathrm{Na}$ = sodium; $\mathrm{RV}$ = reference value; $\mathrm{T}$ Bil = total bilirubin. 

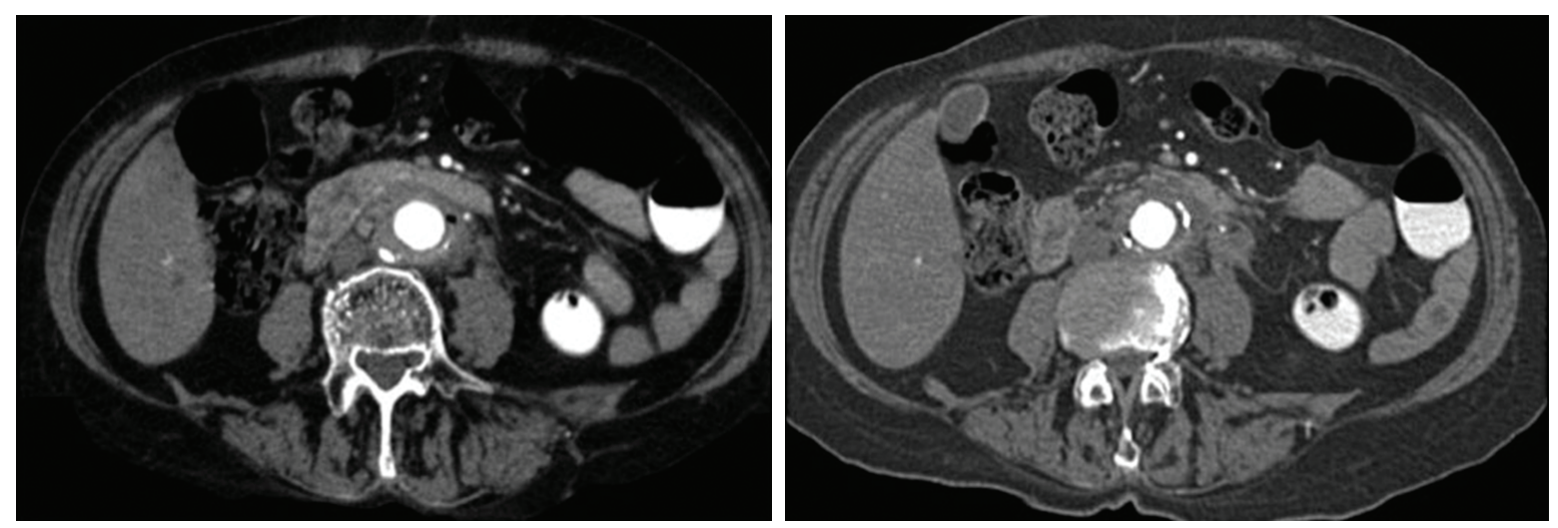

Figure 2 - Axial computed tomography of the abdomen in the arterial phase. Note densification of soft tissue around the aortic endoprosthesis, with gaseous images in between. Note the third portion of duodenum anteriorly displaced.
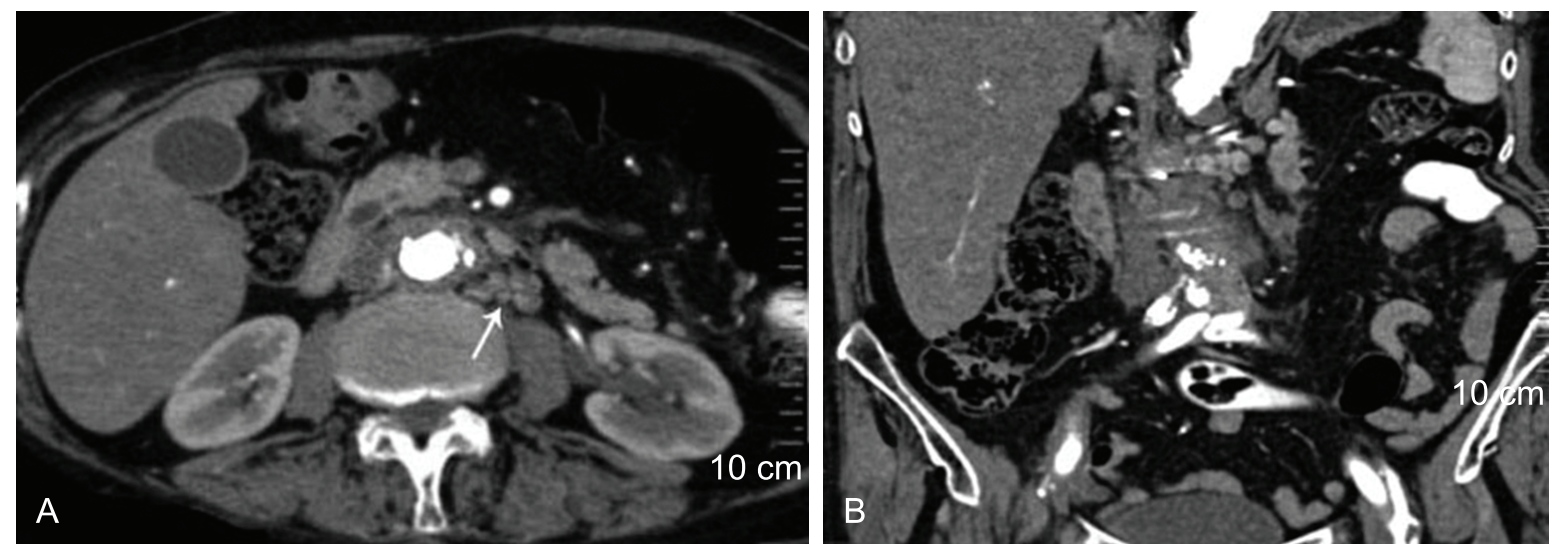

Figure 3 - Computed tomography of the abdomen. A - Axial plane; B - Coronal reconstruction. Both images show para-aortic lymph adenomegaly (arrow).

With the hypothesis of infection of the aortic graft, vancomycin and piperacillin/tazobactan (Tazocin) were prescribed. Surgical treatment consisted in right axillobifemoral bypass with Dacron graft, followed by explant of the infected aortobifemoral graft and ligature of the infrarenal aorta. Surgery was long, eventful, required blood transfusion and the use of vasoactive drugs for hemodynamic stabilization after the infection site manipulation. No aortic or graft enteric fistulas was evidenced during surgery. Culture of the purulent secretion collected from the infection site resulted negative for aerobic bacteria.

The patient died after 4 hours of post operatory due to septic shock.

\section{DISCUSSION}

Since the 1950s, when reconstructive vascular surgery was first reported, ${ }^{1}$ the most feared complication remains as prosthetic infection because of the elevated incidence of death and/ or mutilating surgery that surpasses the rate of $70 \%{ }^{2,3}$ The reported incidence of infection following open abdominal aortic reconstruction ranges from $1 \%$ to $2 \%$. ${ }^{1,4-6}$ This rate may be up to $6 \%$ when the distal anastomoses are made to the femorals, ${ }^{7}$ and appears to be lower $(0.45 \%)$ when endovascular stent implantation is the technique undertaken. ${ }^{8}$

The incidence rate of aortic graft infection (AGI) is thought to be underestimated because of the large variation between the interval of the primary surgery and the recognition of infection, and also because the hospital that manages the complication is usually not the same one where the procedure was first undertaken. ${ }^{1}$

Szilagyi et al. ${ }^{9}$ first classified the infections in three grades, where grades I and II were restricted to the skin and subcutaneous tissues, and grade III involved the aortic graft. Bunt et al. ${ }^{5}$ proposed a classification depending on the presence of aorto enteric fistula. Bandik et al. ${ }^{10}$ classified the infection 
based on the microorganisms involved in the process, characterizing those more frequently observed in acute or late complications. Brissonnière et al. ${ }^{11}$ proposed the classification based on the time of presentation; for example, 3 months before or after the procedure.

AGI occurs frequently in the perioperative period until the first month post operative. ${ }^{12}$ In these cases, Staphylococcus aureus (S. aureus) is the microorganism isolated in $75 \%$ of the cases. ${ }^{13,14}$ This highly virulent microorganism endowed with the capacity of autolysis locally spreads the inflammatory process. More recently, an increase in resistant strains was observed in multiple vascular centers, in Europe and the United States. ${ }^{12}$ Hodgkiss-Harlow et al. ${ }^{12}$ showed four-fold increase (from $10 \%$ to $40 \%$ ) in the incidence of methicillinresistant $S$. aureus (MRSA) in AGI from the year 1990 to 2000. Patient outcomes are less favorable when MRSA is involved compared with methicillinsensitive bacteria. ${ }^{15}$

A second peak of incidence is observed 25 to 41 months after the aortic reconstruction surgery. ${ }^{16,17}$ The number of cases of this group of patients increased recently. In these cases, low virulence microorganisms represent the etiological agents. Staphylococcus epidermidis (S. epidermidis) and Gram-negative bacteria are isolated in $40 \%$ of these cases. Mixed flora infection is reported in $10-15 \% .^{18}$ The infections caused by Gram-negative bacteria present less favorable behavior and are frequently associated with a high incidence of ruptures and anastomotic failure, probably due to their synthesis of endotoxins, elastase, and proteases. ${ }^{19}$ Whenever the $A G I$ is related to Gram-negative bacteria, graft enteric erosion should be suspected, ${ }^{12}$ and Escherichia coli (E. coli)has to be considered first as the causative agent. ${ }^{17}$ In the case reported here, the microbiologic study resulted negative for isolation of the causative microorganism. Negative cultures are reported in $5-20 \%$ of cases. ${ }^{18}$ No fistula was detected during surgery or by computed tomography (CT). Nevertheless, antibiotic therapy was addressed to provide a wide coverage of possible microorganisms. Graft infections caused by fungi are much rarer and are frequently associated with immunosuppressive conditions like malignancies, chemotherapy, or corticosteroid therapy. ${ }^{1}$

Many factors are involved in the pathogenesis of AGI; namely, graft material and method of fabrication, site of implantation, duration of the surgery, use of antibiotic prophylaxis, host defense, nutritional and clinical status of the patient, presence of remote infection, and pathogenicity of the infecting microorganism. ${ }^{10}$ Dacron vascular graft, used in the first surgery of this patient, has been reported to have a greater propensity for bacterial adherence than expanded polytetrafluoroethylene graft. ${ }^{20}$ Arterial interventions requiring a groin incision are associated with a higher incidence of graft infection $(12 \%),{ }^{12}$ probably due to the frequent wound infections in this region. ${ }^{18}$ Inappropriate preparation of the patient in emergency situations augments the risk of graft infection. There also an increased risk when the operation is performed in the presence of ischemic ulcers of the lower limbs or concomitantly with biliary, intestinal, or urologic procedures. ${ }^{7,19}$ Surgical technical difficulties may interfere with the duration of the surgery increasing the risk of operative breaks in sterile techniques. ${ }^{1}$ Revision of a failed vascular reconstruction also increases the probability of graft infection due to the presence of bacteria within the scar tissue, lymphoceles, suture materials, and on the surface of a previous surgical bed. ${ }^{19}$

Bacteria may contact the surgical site by several mechanisms, including colonized mural thrombus of a diseased atherosclerotic plaque or aneurysm; bacteremia; bacteria transport from the wound via lymphatic channels; and patient contamination of the surgical incision by noseto-hand transmission. ${ }^{12}$ The initial step in the infectious process relates to bacterial adhesion to the biomaterial surface, followed by microcolony formation. The inflammatory response involving the surrounding tissues of the graft, impairs the graft healing process, as well as damaging the anastomoses. Gram-negative and Gram-positive bacteria differ in their ability to adhere to biomaterials. In this setting, $S$. aureus has been shown to adhere to suture material better than E. coli. ${ }^{21}$ S. epidermidis produce a biofilm, which is an extracellular mucoid substance involved directly in its adherence capacity to medical devices and development of infection. ${ }^{22,23}$ Bandyk $^{18}$ stated that the graft infections occurring lately are mainly caused by coagulase-negative staphylococci, which characteristically harbor and survive within the biofilm on biomaterial surfaces. With time, a graft biofilm infection can evolve to a more virulent infectious process, with superinfection by other bacteria such as methicillin-sensitive S. aureus or MRSA. ${ }^{12}$ Recent case reports have shown the appearance of unusual etiological agents as Streptococcus equi zooepidemicus in patients who had contact with animals or animal products. ${ }^{24}$ 
After the graft implantation, a thin layer of fibrin covers the porous graft fabric, which is gradually replaced by collagen, resulting in a stable, relatively nonthrombogenic luminal surface resistant to late infection. Bacteria may contaminate the nonendothelized surface of the prosthesis not directly damaging the graft fabric but the surrounding host tissue, which ultimately weakens and disrupts the anastomoses. This disruption leads to a false aneurysm formation, sepsis, graft enteric fistula, hemorrhage, limb loss, or death.1,19 Late graft infections may also occur due to bacterial seeding on the luminal surface after bacteremia caused by dental extraction or dental foci manipulation, urinary tract manipulation, urosepsis, or endovacscular invasive procedures. ${ }^{1,19,25}$

Clinical diagnosis of $A G I$ is sometimes difficult to outline due to the variety of nondescript and vague clinical complaints. Usually mild fever with little systemic repercussion is the first symptom. This pattern is frequently observed in the minimally symptomatic cases related to low-grade infection. The patient of this report presented a first stage of symptoms characterized by weight loss and fever, followed by 2 weeks of pain and clinical deterioration. After this initial phase, or concomitantly, the patient may complain of back and/or abdominal pain, nausea, vomiting, weight loss, anemia, leukocytosis, and elevated erythrocyte sedimentation rate (ESR) and C-Reactive protein. On the other hand, catastrophic presentations may occur and are represented by septic shock, gastrointestinal hemorrhage, and suture-line disruption. ${ }^{17}$ In the case of this report, besides having presented melena and hematochezia, it was not possible to find any aortic or graft enteric fistula. Retroperitoneal abscesses are described in $29 \%$ of cases; inguinal fistula in $14.5 \%$; septic embolism in $11.3 \%$; and hemorrhagic shock in $9.6 \%{ }^{26}$ The aorto-enteric fistula derived from an aortoiliac stent infection manifests itself $63 \%$ of the time as gastrointestinal bleeding.

Occasionally, diagnosis of vascular graft infection can be difficult. Different diagnostic methods can be used to confirm the presence of AGI. CT is considered an accurate method in diagnosing advanced graft infection when, for example, periprosthetic abscess or aortoenteric fistula is present. Perigraft air and/or fluid collections, enhanced perigraft soft tissues, and pseudoaneurysm formation are considered highly suspicious for infection. Considering these findings, CT sensitivity reaches $94 \%$ and specificity $85 \% .^{27}$ In the case of this report, CT enabled a diagnosis with the criteria listed above. Such CT accuracy is not always observed. In a study of 33 cases of AGI, Fukushi et al. ${ }^{28}$ demonstrated $64 \%$ CT sensitivity and $86 \%$ specificity, while Fiorani et al. ${ }^{29}$ reported an overall CT sensitivity of only $55.5 \%$. CT failed to identify the cases with low-grade graft infection. Gutowski, ${ }^{17}$ studying 31 patients with deep aortoiliac graft infection, compared different diagnostic methods and concluded that isotopic study with $99 \mathrm{~m}$ Tc labeled white blood cells showed a sensitivity of $88 \%$, and a specificity of $97 \%$. More recently, the usefulness and accuracy of fluorodeoxyglucose positron emission tomography (FDG-PET) has been studied as a diagnostic tool for vascular graft infection. Activated inflammatory cells show an increased FDG uptake, which makes the method useful for this diagnosis, although its sensitivity varies between $93 \%$ and $91 \%$, and specificity between $64 \%$ and $91 \% .{ }^{28,30}$ Tegler et al. ${ }^{31}$ propose that the hybrid method combining FDG-PET and CT has the potential to become an important imaging tool in the management of suspected aortic graft infections. Magnetic Imaging Resonance (MRI) also represents a useful method for diagnosing AGI. In a series of 59 exams, MRI showed a positive predictive value of $95 \%$ and a negative predictive value of $80 \% .^{32}$

Management of $A G I$ remains contentious. ${ }^{6}$ Most vascular surgeons have little experience of major graft infection due to its comparative rarity. ${ }^{7}$ Before 1986, mortality and amputation rates approached $50 \%$, but it has been decreasing since then. ${ }^{1}$ A recent study comparing different modalities of treatment for AGI showed an early mortality rate of $33 \%$ and a morbidity of $43 \%$, although others show rates between $25 \%$ and $35 \% .{ }^{33}$ Batt et al. ${ }^{6}$ believe that these rates appear more attributable to the patient's general condition than the choice of treatment.

In general, the modalities of treatment are divided into surgical or conservative. Conservative therapy involves long-term antibiotic therapy. Surgical techniques include in situ graft replacement with or without the implant of antibiotics beads on the surgical bed, or the implant of an antibiotic embedded graft; and extra site graft replacement. Both techniques include infected graft explant. The choice of treatment and its consequent outcome will depend on the extension of the infection, the virulence of the involved agent, the presence (or absence) of a biofilm in the infection site, and the clinical status of the patient. 


\section{CONCLUSION}

Despite technological advances regarding the manufacture of vascular grafts, as well as the advances in surgical techniques, infectious complications, although uncommon, are still a concern of vascular surgeons. Late prosthetic infections are among the most feared complications. The insidious and non-specific clinical presentation often hampers the diagnosis. Several therapeutic modalities are proposed, but better outcomes are linked to the patient's clinical status. In this bleak scenario, the earlier the diagnosis the greater the possibility of a favorable outcome.

\section{REFERENCES}

1. Chiesa R, Astore S, Frigerio L, et al. Vascular prosthetic graft infection: epipdemiology, bacteriology, pathogenesis and treatment. Acta Chir Belg. 2002;102:238-47. PMid:12244902.

2. Mansfield AO, Sriussadaporn S, Stotter A. The infected vascular graft. Hospital Update 1992; September 1-6.

3. Naylor AR, Clark S, London NJM, Sayers RD, Macpherson DS, Barrie WW. Treatment of major aortic graft infection: preliminary experience with total graft excision and in situ replacement with a rifampicin bonded prosthesis. Eur $\mathrm{J}$ Endovasc Surg. 1995;9:252-6. http://dx.doi.org/10.1016/ S1078-5884(05)80101-7

4. Hayes PD, Nasim A, London NJ, et al. In situ replacement of infected aortic grafts with rifampicin-bonded prosthesis: the Leicester experience (1992 to 1998). J Vasc Surg. 1999;30:92-8. http://dx.doi.org/10.1016/S07415214(99)70180-1

5. Bunt TJ. Synthetic vascular graft infections. Surgery. 1983;93:733-46. PMid:6344294.

6. Batt M, Jean-Baptiste E, O'Connor S, et al. Contemporary management of infrarenal aortic graft infection: early and late results in 82 patients. Vascular. 2012;20:129-37. PMid:22661612. http://dx.doi.org/10.1258/vasc.2011.oa0315

7. Quick CRG, Vassalo DJ, Colin JF, Heddle RM. Conservative treatment of major aortic graft infection. Eur $\mathrm{J}$ Vasc Surg. 1990;4:63-7. http://dx.doi.org/10.1016/S0950$821 \mathrm{X}(05) 80040-4$

8. Ducasse E, Calisti A, Speziale F, Rizzo L, Misuraca M, Fiorani P. Aortoiliac stent graft infection: current problems and management. Ann Vasc Surg. 2004;18:521-6. PMid:15534730. http://dx.doi.org/10.1007/s10016-004-0075-9

9. Szylagyi DE, Smith RF, Elliot JP, et al. Infection in arterial reconstruction with synthetic grafts. Ann
Surg. 1972,176:321-33. http://dx.doi.org/10.1097/00000658197209000-00008

10. Bandyk DF. Aortic graft infection. Semin Vasc Surg. 1990;3:122.

11. Association Universitaire de Recherche en Chirurgie, Goeau-Brissonnere O, Doyon F. et al. Étude prospective de 597 prothèses aorto-femorales: resultats preliminaires. 4th Congres International sur la prophylaxie des infections; 1996 Mai 6-7; Nice, France. French.

12. Hodgkiss-Harlow KD, Bandik DF. Antibiotic therapy of aortic graft infection: treatment and prevention recommendations. Semin Vasc Surg. 2011;24:191-8. PMid:22230673. http:// dx.doi.org/10.1053/j.semvascsurg.2011.10.013

13. Bandyk DF. Vascular surgical site infection: risks factors and prevention. Semin Vasc Surg. 2008;21:119-23. PMid:18774446. http://dx.doi.org/10.1053/j. semvascsurg.2008.05.008

14. Armstrong PA, Back MR, Bandyk DF, et al. Selective application of sartorius muscle flap and aggressive staged surgical debridement can influence long-term outcomes of complex graft infections. J Vasc Surg. 2007;46:71-8. PMid:17606124. http://dx.doi.org/10.1016/j.jvs.2007.02.058

15. Cowie SE, Ma I, Lee SK, et al. Nosocomial MRSA infection in vascular patients: impact on patient outcome Vasc Endovasc Surg. 2005;39:327-34.

16. Goldstone J, Moore WS. Infection in vascular prosthesis: clinical manifestations and surgical manegement. Am J Surg. 1974;128:225-33. http://dx.doi.org/10.1016/00029610(74)90097-X

17. Gustowski P. Aortoiliac graft infection as a diagnostic and treatment problem. Ann Acad Med Stetin.1998;suppl 41:1-72.

18. Bandyk DF. Vascular grafts infections: epidemiology, microbiology, pathogenesis and prevention. In: Bernhard VM, Towes J, editors. Complications in vascular surgery. St Louis: Quality Medical Publishing; 1991. p. 223-34.

19. Bandyk DF. Infection in prosthetic vascular grafts. In: Rutherford RB, editor. Vascular surgery. 5th ed. Philadelphia: Saunders; 2000. p. 773-51.

20. Boyce B. Physical characteristis of expanded polytetrafluorethylene grafts. In: Stanley J, editor. Biologic and synthetic vascular prostheses. Michigan: Grune \& Stratton; 1982. p. 553-61.

21. Chih-Chang C, Williams DF. Effects of physical configuration and chemical structure of materials on bacterial adhesion. Am J Surg. 1984;147:197-204. http://dx.doi.org/10.1016/00029610(84)90088-6

22. Bandyk DF, Berni GA, Thiele BL, Towne JB. Aortofemoral graft infection due to Staphylococcus epidermidis. Arch Surg. 1984;119:102-8. http://dx.doi.org/10.1001/ archsurg.1984.01390130084015 
23. Arciola $C R$, Montanaro $L$, Baldassarri L, et al. Slime production by Staphylococci isolated from prosthesis-associated infections. New Microbiol. 1999:22:337-41. PMid:10555204.

24. Altreuter M, Lange C, Myhre HO, Hannula R. Aortic graft infection and mycotic aneurysm with Streptococcus equi zooepidemicus: two cases with favorable outcome of antibiotic treatment. Vascular [Internet]. 2012 Feb 28; [Epub ahead of print; cited 2012 Dec 17].

25. Veger HT, Hederman Joosten PP, Thoma SR, Visser MJ. Infection of endovascular abdominal aortic aneurysm stent graft after urosepsis: case report and review of the literature. Vascular [Internet]. 2012 May 22; [Epub ahead of print; cited 2012 Dec 17]. PMid:22619381.

26. Fiorani P, Speziale F, Calisti A, et al. Endovascular graft infection: preliminary results of an international enquiry. J Endovasc Ther. 2003;10:919-27. http://dx.doi. org/10.1583/1545-1550(2003)010<0919:EGIPRO>2.0.CO;2

27. Low RN, Wall SD, Jeffrey RB, et al. Aortoenteric fistula and perigraft infection: evaluation with $C T$. Radiology. 1990;175:157-62. PMid:2315475.

28. Fukushi K, Ishida $\mathrm{Y}$, Higashi M, et al. Detection of aortic graft infection by flouorodeoxyglucose positron emission tomography: Comparison with computed tomographic findings. J Vasc Surg. 2005;42:919-25. PMid:16275448. http://dx.doi.org/10.1016/j.jvs.2005.07.038

29. Fiorani P, Speziale F, Rizzo L, et al. Detection of aortic graft infection with leukocytes labeled with technetium 99m-hexametazine. J Vasc Surg. 2007;21:586-92.

30. Keidar Z, Engel A, Hoffman A, et al. Prosthetic vascular graft infection: the role of 18F-FDG PET/CT. J Nucl Med. 2007;48:1230-6. PMid:17631553. http://dx.doi. org/10.2967/jnumed.107.040253

31. Tegler G, Sörensen J, Björck M, et al. Detection of aortic graft infection by 18-fluorodeoxyglucose positron emission tomography combined with computed tomography. J Vasc Surg. 2007;45:828-30. PMid:17398393. http://dx.doi. org/10.1016/j.jvs.2006.12.018

32. Shahidi S, Eskil A, Lundof E, Klaerke A, Jensen BS. Detection of abdominal aortic graft infection: comparison of magnetic resonance imaging and indium-labeled white blood cell scanning. Ann Vasc Surg. 2007;21:586-92. PMid:17823040. http://dx.doi.org/10.1016/j.avsg.2007.03.018

33. Lawrence PF. Conservative treatment of aortic graft infection. Semin Vascular Surg. 2011;24:199-204. PMid:22230674. http://dx.doi.org/10.1053/j.semvascsurg.2011.10.014

\section{Conflict of interest: None.}

Submitted on: $18^{\text {th }}$ December 2012

Accept on: $5^{\text {th }}$ March 2013

Correspondence: Divisão de Clínica Médica

Av. Prof. Lineu Prestes, 2565 - Cidade Universitária - São Paulo/SP - Brazil

CEP: 05508-000 - Phone: +55 (11) 3091-9200

E-mail: ffcampos@usp.br 
